\title{
La renovación del anarquismo en el Uruguay: la Federación Anarquista Uruguaya entre 1956 y 1967
}

\author{
EDUARDO REY TRISTÁN*
}

\begin{abstract}
Resumo: $O$ anarquismo uruguaio, força dominante no meio operário nas primeiras décadas do século XX, após seu ostracismo entre 1929 e 1956, viveu um segundo momento de destaque nas lutas sociais do país durante os anos sessenta. Sua organização na Federação Anarquista Uruguaia, em 1956, lhe permitiu constituir-se, novamente, numa força política e social destacada dentro da esquerda. Este trabalho estuda a evolução do anarquismo no Uruguaí entre 1956 e 1967. Inicia-se com o processo de criação de sua principal organização política legal nesse período, a FAU, e analisa-se sua trajetória até a decretação de sua ilegalidade, em dezembro de 1967: organização, debates internos, ideologia e concepção de revolução.
\end{abstract}

Abstract: In the beginning of the $20^{\text {th }}$ century, anarchism was the dominant force in the social and worker movements, but since 1929 until 1956, it lost all of its influence. Its reorganization into the Uruguayan Anarchist Federation (FAU) in 1956, was the key to recover its importance into the Uruguayan left and to have a new period of importance in the social movements. This essay studies the evolution of anarchism in Uruguay between 1956 and 1967. It begins with the foundation process of the main political legal organization of the Uruguayan anarchism in the period studied, FAU, and analyzes its evolution until its ilegalization in 1967, december: internal organization, internal debats, ideology and revolutionary proposals.

Palavras-chave: Federação Anarquista Uruguaia (FAU). Esquerda revolucionária anarquista. Uruguai.

Key words: Uruguayan Anarchist Federation (FAU). Revolutionary anarchist left. Uruguay.

* Doctor en Historia e Investigador Posdoctoral de la Universidad de Santiago de Compostela (España). Trabajo realizado en el marco del proyecto de Investigación BHA 2002-01644 (MCYT, España). E.mail: ereyt@usc.es 


\section{La Renovación}

Dos circunstancias contribuyeron a comienzos de la década de los cincuenta al inicio del movimiento de reorganización y de actualización de la vieja tradición libertaria. Por una parte, los importantes conflictos sindicales vividos en los años 1951 y 1952, los Gremios Solidarios, que significaron la reactualización de una línea sindical combativa poco presente en las últimas dos décadas, así como en la agitación de conciencias y actitudes entre viejos y nuevos militantes anarquistas (Cores, 1989, p. 195); por otra, el desarrollo de nuevos núcleos organizados o la revitalización de algunos ya existentes. Entre los primeros se cuenta por ejemplo el Ateneo Libre Cerro - La Teja, institución cultural de referencia del anarquismo desde su creación en enero de $1952 ;{ }^{1}$ entre los segundos destacaban las Juventudes Libertarias, conformadas sobre todo por estudiantes universitarios, muchos también militantes de la Federación de Estudiantes Universitarios del Uruguay (FEUU), que aportaron los debates y posiciones defendidos en la movilización universitaria desde fines de los años 40, especialmente el tercerismo y el antiimperialismo; ${ }^{2}$ y el periódico Voluntad, nacido en 1938 y desde 1953 vehículo de comunicación y difusión de las ideas renovadoras, y núcleo impulsor del proceso en lo orgánico. En estas organizaciones crecieron políticamente quienes luego serían líderes de la FAU, si bien cabe destacar su estrecha relación con los viejos militantes, portadores de la experiencia de movilización y lucha anteriores, así como con los exiliados españoles. ${ }^{3}$

1 El Cerro y La Teja eran barrios obreros de tradición anarquista, vinculados a la industria frigorífica de la carne y protagonistas de los Gremios Solidarios. El Ateneo se levantaba en el lugar de instituciones precursoras entre 1929 y 1948, y era puente entre las nuevas propuestas y las viejas tradiciones, lugar de encuentro, relación e intercambio político y cultural (Voluntad, marzo 1952, n 117, p. 3: "Ateneo Libre Cerro-La Teja", y Juan Carlos Mechoso, miembro fundador y dirigente de FAU, entrevista con el autor, Montevideo, 9/11/1999).

2 Por tercerismo se entiende una posición específica en política internacional (Solari, 1990, p. 645). Defendía la adopción de una línea política independiente de las dos grandes potencias, y giró en torno a algunas ideas muy determinadas, si bien con importantes variaciones entre sus defensores: neutralidad, nacionalismo, internacionalismo y antiimperialismo. Fue habitual en la FEUU en los años cuarenta, y se incorporó a través de muchos militantes estudiantiles a la izquierda política en los años cincuenta (Rey Tristán, 2001).

3 Según Carlos Rivera, simpatizante en estos años y posterior miembro del MLN-T, los exiliados fueron elemento destacado en el aprendizaje y politización de muchos futuros militantes libertarios, e incluso de otros que con el tiempo acabaron en otras filas de la izquierda revolucionaria (entrevista con el autor, Montevideo, $26 / 11 / 2000)$. 
Las primeras tareas conducentes a la creación de una organización política del anarquismo comenzaron a mediados de 1953 con el llamamiento realizado desde las páginas de Voluntad para la celebración de una conferencia libertaria que reuniese a toda la militancia dispersa, que reivindicase los postulados históricos del anarquismo, y que organizase a todos los núcleos existentes, como vía para la superación de su falta de influencia socio política. ${ }^{4} \mathrm{El}$ llamamiento tuvo un efecto positivo, pues desde entonces se aprecia tanto un intenso desarrollo de los grupos libertarios existentes como la aparición de otros nuevos, como fue el caso de la Agrupación Libertaria Cerro - La Teja en 1955, clave en el proceso a partir de entonces. Además, en todos estos núcleos, y hasta 1956, el debate acerca de la conveniencia, posibilidades y formas de una organización política anarquista sería una constante.

Esa primera propuesta de dinamización del movimiento anarquista uruguayo dio sus primeros frutos a fines de 1955 con la constitución de una comisión organizadora de un Pleno Nacional Anarquista (PNA), la aprobación de un temario de discusión para su preparación, y la publicación de un boletín mensual para la difusión de los trabajos y debates. ${ }^{5}$ El Pleno tuvo lugar entre el 14 de abril y el 5 de mayo de 1956, contó aproximadamente con unas 250 personas, y fue el momento clave de todo el proceso reorganizador. No sólo logró el definitivo contacto de toda la militancia dispersa o dio el primer paso en la creación de una organización política del anarquismo uruguayo, sino que además estableció las líneas ideológicas y de acción básicas por las cuales transitaría éste en los siguientes años, y que las instancias constituyentes de la definitiva Federación Anarquista no transformarían en lo fundamental. De él salieron las estructuras que organizaron, en los siguientes cinco meses, el definitivo Congreso Constituyente de la Federación Anarquista (octubre de 1956). Ese período se caracterizó por un cierto auge organizativo en el movimiento anarquista, la puesta en marcha de alguna de las propuestas salidas del Pleno, la aparición de nuevas agrupaciones barriales resultado del impulso

4 "Necesario es que el anarquismo se conforme en una fuerza orgánica coherente capaz de gravitar en los acontecimientos sociales y hacer cambiar el rumbo de la historia. (...) nos lo imponen las circunstancias, el que nos decidamos (...) a organizar a nuestra militancia" (Voluntad, agosto 1953, nº 132, p. 3: "Hacia la realización de un Congreso Anarquista en el País. Por un Movimiento Libertario Fuerte y Organizado").

5 Voluntad, octubre 1955, n 154: "El Pleno Nacional Libertario deberá ser expresión de madurez doctrinaria y militante de nuestro movimiento". Voluntad, noviembre 1955, n 155: "Proyecto de Temario del PNA". 
a la militancia existente en algunas zonas, la transformación de Voluntad en órgano del movimiento anarquista 6 y, cómo no, por un intenso trabajo de organización.

El Congreso Constituyente de la Federación Anarquista Uruguaya fue un punto de inflexión en la evolución del movimiento libertario en el país. Con ésta no sólo se abría una nueva etapa; representaba además un hito de especial importancia en su tradición. El viejo anarcosindicalismo dejaba paso a concepciones más acordes con la situación política y social del momento. A la nueva organización se incorporaba tanto el sector obrero como aquellos provenientes del ámbito estudiantil, del cultural o del barrial. Cada uno aportaba nuevos elementos teóricos, organizativos y de trabajo, lo que enriquecía considerablemente el debate, y entre todos se coordinaban para constituirse en una alternativa política, social y sindical, especialmente en el seno de la izquierda y de las organizaciones populares.

PNA y Congreso Constituyente representaban dos partes o momentos de un mismo proceso organizativo, a pesar de los meses que los distanciaron. Hubo continuidad en trabajo e ideas, y mientras que el primero representó la definición de las propuestas ideológicas básicas que defendería el anarquismo uruguayo en los siguientes años, el segundo avanzó en la definición de la estructura común, la Federación. Los acuerdos del Pleno, ${ }^{7}$ veremos, fueron adoptados mayoritariamente: algunos con leves modificaciones, y otros ratificados sin cambio. Las tareas fundamentales del Congreso Constituyente se orientaron a definir el nombre de la nueva organización, a su Declaración de Principios y a su Carta Orgánica. Los dos últimos fueron los principales documentos de la reunión. Representaban los acuerdos básicos de ese conjunto de militancia que estaba organizándose, continuando la línea ideológica establecida en los Acuerdos del PNA (tanto en sus propuestas maximalistas como en sus fines más inmediatos) la primera, y estableciendo derechos y deberes la segunda. ${ }^{8}$

6 Este hecho provocó el primer conflicto interno del período: el pequeño grupo de militantes que editaba Voluntad desde sus inicios, y que mantenía una línea individualista y antiorganicista desacorde con la Federación, no aceptó el acuerdo de la Asamblea del Grupo Editor (Voluntad, agosto 1956, $\mathrm{n}^{2}$ 163) para la transformación de la publicación en órgano oficial del movimiento anarquista. Continuó editando su versión hasta 1965, aunque sin incidencia apreciable en el anarquismo militante o en el medio obrero. La convivencia de las dos cabeceras duró hasta mayo de 1957, en que la FAU cambió la suya por Lucha Libertaria.

7 Acuerdos del Pleno Nacional Anarquista, mayo 1956, Montevideo (Archivo FAU).

8 Voluntad, noviembre 1956, $\mathrm{n}^{\mathrm{9}}$ 166: "Declaración de Principios de la Federación Anarquista Uruguaya" y Boletín de la FAU n² 6, marzo 1958, Montevideo (Archivo FAU). 
En la base de todo el análisis y propuestas realizadas a lo largo de estos años se encontraban algunos posicionamientos ideológicos fundamentales del anarquismo, a partir de los que se interpretó la realidad y se definieron posturas: la crítica a la estatización, el clientelismo y la forma de hacer política de los partidos tradicionales, ${ }^{9}$ frente a lo que reivindicaban una posición antiestatista y libertaria; la condena del sistema capitalista, responsable de la crisis nacional, y cuya destrucción era fundamental para la transformación social; y la defensa de la organización social de base en todos los ámbitos (de producción, consumo, cultural, etc.), que también se entendía para la propia organización y militancia, así como para el fomento de la participación en la vida sindical y estudiantil.

Todos estos elementos los encontramos constantemente en los documentos salidos del PNA. Estos recogen acuerdos variados sobre diferentes cuestiones políticas nacionales e internacionales. De entre los temas debatidos en estos años, y dada la importancia que tendrían para la evolución de la Federación desde entonces, cabe destacar dos: el referido a los problemas internacionales, y el del movimiento sindical. El primero partía de la citada línea anticapitalista, antiestatista, y en pro de una acción directa de los pueblos para lograr la transformación en un sentido socialista y libertario. Lo más significativo es su incipiente latinoamericanismo, que sería impulsado poco después por la I Conferencia Anarquista Americana (celebrada en Montevideo en 1957),,$^{10}$ y que era novedoso en el anarquismo uruguayo. Se relaciona, además, con el apoyo declarado a las luchas coloniales del momento (antiimperialismo), y a la oposición a la política de bloques y confrontación entre las dos grandes potencias (tercermundismo). Todo ello muestra claramente las nuevas bases políticas de la Federación en este tema, que serán fundamentales a la hora de comprender la influencia de la Revolución Cubana y algunas de las líneas que se darán en el seno de la FAU en la siguiente década.

9 Los partidos de izquierda tampoco se libran de las críticas: el PSU por su estéril parlamentarismo, y el PCU por su línea soviética y lo que consideran acción negativa en el movimiento obrero.

10 Voluntad, abril 1957, n" 170: "14 al 21 de abril en Montevideo Conferencia Anarquista Americana". Lucha Libertaria, mayo 1957, $\mathrm{n}^{2}$ 171: "Significación y trascendencia de la I Conferencia Anarquista Americana"; y junio 1957, $\mathrm{n}^{\underline{9}}$ 172: "Conferencia Anarquista Americana: Disociación nacionalista de los pueblos americanos". 
El segundo de los debates mencionados, el referido al movimiento sindical, ya había acaparado las sesiones más concurridas del PNA,11 momento en el que se asentaron sus bases, profundizadas y maduradas en su formulación definitiva en el Congreso Constituyente. En su análisis de partida se aprecia una visión muy crítica con su situación, entendida como resultado de la influencia dominante de las corrientes legalistas - especialmente comunista -, dependientes de hegemonías e intereses ajenos a los trabajadores, así como de la falta de control de éstos sobre sus gremios debido, entre otras razones, a su burocratización. En el aspecto interno, se avanzó respecto a la tradicional línea libertaria en este campo al analizar de forma realista la pérdida de influencia en el medio obrero, al dar por superadas las viejas tradiciones anarcosindicalistas, y al abogar por nuevas formulaciones tácticas adecuadas a los nuevos y difíciles tiempos. Muestra de la nueva línea era la ruptura con la vieja distinción entre sindicalistas legalistas y de acción directa, o con el criticismo a toda legislación laboral, discurso que chocaba con la práctica individual, en la que se aceptaban sus beneficios. Un nuevo Plan de Acción Sindical estableció las claves del trabajo futuro de la FAU en este ámbito: activa militancia, afirmación de la acción directa como método de lucha y forma de aprendizaje de cara a una futura sociedad libertaria, y conjugación los principios e ideales anarquistas con la lucha por reivindicaciones inmediatas. Se conjugaban objetivos maximalistas con otros más concretos que afectaban a la organización de la producción y el trabajo, al salario y su ajuste con el coste de vida, a las condiciones de trabajo y jornada, o a la perfección de los métodos de lucha sindical. En lo orgánico, se defendía el aumento de la participación anarquista activa en los sindicatos: creando grupos afines en ellos, estableciendo redes de vinculación, y actuando con novedosos (y bien diferentes) criterios. ${ }^{12}$ Además, desde el PNA se adoptó una postura clara respecto a la organización del movimiento obrero, que tendría un peso importante en el proceso de unidad de la década siguiente: estructuración en una central única de bases federales, y sin hegemonías de ningún sector. La formulación definitiva del Plan de Acción Sindical fue aprobada por el Congreso Constituyente y ratificada prácticamente sin cambios un año después en el I Congreso de la FAU. Fue elemento clave en el trabajo de la Federación en los siguientes años, así como en la recuperación parcial de la tradicional influencia libertaria en el movimiento sindical.

11 Voluntad, mayo 1956, n 160: "El Pleno Nacional Anarquista logró sus objetivos".

12 Estos incluían una asunción de responsabilidades que implicaba no rehuir cargos (aunque siempre con conocimiento del grupo y ética libertaria), así como una crítica constructiva y un trato de equidad con los militantes no anarquistas. 
A partir de noviembre de 1956, por tanto, se abrió una nueva etapa en el movimiento anarquista uruguayo, que estaría representada hasta diciembre de 1967 por su organización legal, la FAU. En estos años hubo dos períodos claramente diferenciados: uno hasta 1964, en que nos encontramos con una organización que representa casi a la totalidad del movimiento (a excepción de los individualistas), dedicada sobre todo a su crecimiento y consolidación, a la consecución de una estructura interna acorde con los planteamientos mayoritarios, con un activo debate acerca de su actuación en el movimiento sindical, y que apoya firmemente a la Revolución Cubana. Y un segundo que se inicia a partir de 1964 con la ruptura provocada por las diferentes posturas en torno a Cuba, así como por asuntos referidos a organización y funcionamiento interno de la Federación. En él se profundizará en la coordinación con otros grupos de tendencia revolucionaria - aunque no libertarios - con los que se compartirán espacios comunes, y se avanzará en una línea de acción más radical, con estructuras semi clandestinas, y la profundización en una propuesta política cuya influencia principal está vinculada a la herencia de la Revolución Cubana.

\section{Desarrollo y consolidación}

Los primeros ocho años de la vida de FAU estuvieron marcados por dos tareas y una polémica. Las primeras fueron: la búsqueda de una correcta y funcional forma organizativa, que ocupó el debate de la Federación hasta iniciados los sesenta; y la actividad en el seno del movimiento sindical. La polémica se desarrolló desde 1960 en torno a la postura a adoptar sobre la Revolución Cubana, lo que llevaría, junto a enfrentadas opiniones en las tareas anteriores, a la escisión de FAU en 1964.

Los debates en torno a la estructura de la Federación fueron constantes en sus comienzos, y tanto en el I Congreso ordinario (noviembre de 1957), ${ }^{13}$ como en numerosas instancias posteriores (plenos de militantes, plenos ordinarios y plenos extraordinarios), encontramos abundantes testimonios. En estos primeros años aún no se llegaba al fondo de la polémica. Pero comenzaban a mostrarse, todavía no completamente formadas, las dos principales tendencias que se dieron en el seno de la FAU. Por una parte, se aprecia una línea que defendía la más pura actividad asamblearia y

13 Lucha Libertaria, noviembre 1957, $\mathrm{n}^{2}$ 176: "El Primer Congreso Ordinario de la FAU". 
participativa, y que promovía el papel central del Pleno de militantes como órgano fundamental de la Federación entre congresos. Éste figuraba en la Carta Orgánica como recurso especial, ${ }^{14}$ y sin carácter resolutivo, sólo consultivo. Consta en cambio, que al menos durante ciertos meses de 1958 actuó con aquél carácter, tomando decisiones en cuanto a organización de las agrupaciones y suplantando al Consejo Federal en esas funciones. ${ }^{15}$ Por otra parte, una segunda línea defendía el peso de éste último órgano, instancia de organización y decisión de la vida de la Federación entre congresos, según había señalado la Carta Orgánica en 1956. La opción por éste frente al pleno de militantes implicaba dar más peso a una concepción centralizadora, y se justificaba en la necesidad de agilidad en la toma de decisiones referidas a la vida de la organización y a su trabajo en los ámbitos de masas.

En lo orgánico, cabe señalar también el crecimiento de la FAU en estos años. Volcaron esfuerzos en las tareas de prensa y difusión. Así, Lucha Libertaria, su órgano de prensa, salió mensualmente entre mayo de 1957 y julio de 1961. En 1962 aún aparecerían tres números, y en abril de 1965 un último y solitario ejemplar. Probablemente su práctica desaparición a partir de 1962 estuvo relacionada con las diferencias en el seno de la organización, y quizás con la aparición del diario Época, punto de encuentro entre 1962 y 1966 de los grupos de tendencia revolucionaria, y la participación en él de uno de los sectores de la FAU. Contaron también con una audición radial de 10 minutos todos los martes entre enero de 1959 y, al menos, fines de 1960.16 Carecemos, en todo caso, de datos concretos acerca de las agrupaciones, número de militantes, etc., por lo que no es posible valorar el posible crecimiento anarquista en el período.

$\mathrm{La}$ actividad sindical fue una de las principales en la FAU, y en la que se situaba una de sus fuentes de militancia más importantes. Sobre ella y sus formas de actuación radicó el segundo debate permanente a partir de 1957. Los dos rasgos principales en este ámbito fueron: su decidida campaña pro central única, y el apoyo total a las luchas del momento, especialmente a aquellas que aportaban elementos novedosos y radicales al sindicalismo uruguayo. El debate sobre la unidad, ya viejo en el sindicalismo

14 FAU, Boletín de la FAU, $\mathrm{n}^{\circ}$ 6, marzo 1958, "Carta Orgánica", art. 23. (Archivo FAU).

15 Lucha Libertaria, septiembre 1958, n² 185: "Importantes acuerdos del Pleno de Militantes".

16 Lucha Libertaria, enero-febrero 1959, $\mathrm{n}^{2}$ 189: "Lucha Libertaria radial"; y noviembrediciembre 1960, n² 200: "Los martes CX 44 Radio América. Hora 21. Habla Lucha Libertaria". 
uruguayo, había resurgido con fuerza en 1956 a partir de una huelga de la industria frigorífica acompañada por gran parte del movimiento obrero con medidas de solidaridad. Desde entonces y hasta la creación de la Convención Nacional de Trabajadores (CNT) en 1964, el tema fue una constante en la izquierda, y el anarquismo participó en él con una propuesta de la que más adelante la CNT recogerá importantes aspectos.

La propuesta de FAU en torno a la central única ya había sido esbozada en el Plan de Acción Sindical aprobado en el Congreso Constituyente. Reflejaba al tiempo su concepción del movimiento sindical: era una necesidad para enfrentar al Estado y el capital, y debería cuajar en una central independiente (de partidos, Estado o patronales), sin caudillismos, sectarismos ni hegemonías políticas (uno de los aspectos más duramente criticados por la prensa anarquista, en especial referencia al dominio comunista y el copamiento ideológico y de puestos que procuraba siempre en las organizaciones sindicales), que llevasen a la división. Para ello era fundamental la libertad de opinión y criterio, la unidad de acción y un programa de acción común; con formas de lucha y planteos programáticos que sean los que en cada caso vayan decidiendo los trabajadores desde las asambleas sindicales. El movimiento sindical tenía para el anarquismo una función doble e interrelacionada: de lucha inmediata (resistencia frente al Estado y el capitalismo, defensa de las libertades gremiales y públicas y las mejoras en las condiciones de vida y trabajo) y de objetivos finalistas (progresiva transformación revolucionaria de las bases mismas del sistema, sustituyéndolo por estructuras organizativas basadas en la autogestión popular). ${ }^{17}$ Los criterios de independencia y oposición a burocracias sindicales eran compartidos por el sindicalismo autónomo, y se traducían en propuestas prácticas organizativas que luego se verán reflejadas en la CTU desde 1961 o la CNT desde 1964: no existencia de dirigentes rentados, incompatibilidad entre dirección sindical y participación en cargos políticos electivos, o afiliación internacional que alinease a la central.

Otra de las banderas de la propuesta sindical anarquista en estos años fue la de la unidad obrero-estudiantil, puesta en práctica a fines de 1958 con motivo del conflicto por la aprobación de la Ley Orgánica de la Universidad. La huelga y manifestaciones fueron apoyadas por el movimiento obrero, y desde esos momentos se levantó la conocida consigna que estaría presente en las luchas

17 Lucha Libertaria, noviembre 1958, $\mathrm{n}^{\mathrm{n}}$ 187: "Los trabajadores, por su acción directa, harán la unidad". 
de fines de la década siguiente: obreros y estudiantes juntos y adelante. Si bien esta confluencia ya se había producido en casos anteriores (huelga universitaria de 1951 y luchas de los gremios solidarios), sería desde ahora que tomase fuerza y continuidad. El conflicto universitario tenía además las características de acción directa y autogestión defendidas por el anarquismo, como mostró en la ocupación de la Universidad durante las semanas del conflicto, y a la que fueron invitados los líderes obreros.

La otra lucha que aportó elementos relativamente novedosos a la acción sindical en estos años fue la de FUNSA, sindicato del caucho que durante la década siguiente sería bandera de la acción directa bajo dirección de un decidido núcleo libertario. En esa fábrica, a fines de 1958, se realizó por primera vez una ocupación del centro de trabajo con puesta en marcha de la producción bajo control obrero. Este hito de las luchas sindicales en el Uruguay, significó para la FAU la reafirmación de algunos de sus principios y propuestas: la negación de la acción legalista en las luchas obreras y la defensa de la acción directa de los trabajadores; la afirmación de la importancia del sindicalismo entre los trabajadores (sin sindicato no hay leyes que valgan); la afirmación de la importancia de la educación y formación de los trabajadores, así como de una Universidad orientada a formar técnicos para la sociedad, no para el capital; y la importancia de la solidaridad externa de los sindicatos vinculados, pues así las ocupaciones podrán extenderse y-ipor qué no? - podrán ir cambiando de arma de lucha meramente reivindicativa a modalidad de acción revolucionaria. ${ }^{18}$

\section{El debate en torno a la Revolución Cubana}

El debate en torno a la Revolución Cubana definió y distanció posturas en el seno de una Federación que se había levantado sobre un consenso común de anarquistas de diversas tendencias teóricas y orígenes militantes, y de diferentes formas de comprender la lucha por los objetivos comunes definidos. La postura inicial, incluso antes del triunfo en enero de 1959, era acorde con las definiciones iniciales en materia internacional.19 Cuba era para la

18 Lucha Libertaria, diciembre 1958, n² 188: "La ocupación de fábricas. Un nuevo método de lucha. Una nueva responsabilidad". La última cita es reflejo de la nueva idea libertaria en sus reivindicaciones: la conjugación de las inmediatas y el objetivo revolucionario, que no sólo es posible y deseable, sino una vía a seguir.

19 Lucha Libertaria, abril 1958, $\mathrm{n}^{2}$ 181: "Reedición de una gran jornada". Entre las reivindicaciones que FAU plantea en su acto del $1^{2}$ de mayo de 1958 , ya se encontraba 
FAU, al igual que para el resto de la izquierda latinoamericana, una esperanza firme (...) Ilamada a repercutir hondamente en esta América llena de venalidad y nacionalismo entregadores. Aún no se hacía un análisis profundo de la revolución. Era tal, había derrocado a una dictadura, y constituía el ejemplo de lo posible para el resto del continente, suficiente para estar a su lado y trabajar para que no siguiese el camino frustrado de las revoluciones guatemalteca y boliviana: los pueblos de América tendrán que defenderlos, porque si los dejamos destruir, nos estaremos suicidando.20 Todo ello se tradujo en la pronta creación de comités de apoyo y actos reivindicativos de la revolución (Rey Tristán, 2002).

Pero a medida que evolucionaba el proceso revolucionario cubano, las opiniones en torno a él en el seno de la FAU fueron divergiendo. Hubo tres momentos importantes para entender la profundización de unas diferencias que llevarían - sumadas a otras cuestiones - a la escisión de la Federación: el primero fue la resolución de apoyo a Cuba aprobada en octubre de 1960. Su adopción hay que entenderla no sólo por la evolución del castrismo, que ya había dado un giro significativo hacia el apoyo soviético; estuvo motivada, principalmente por diferencias en el seno de la FAU respecto a la comprensión y asunción de esa evolución. Su línea argumental siguió la ya esbozada en 1959, y fue la base teórica del apoyo dado y mantenido durante toda la década al proceso revolucionario cubano: la revolución supuso una serie de logros del y para el pueblo cubano (reforma agraria, desarrollo de la educación, de la sanidad, de la vivienda o de la higiene), y si bien no era el ideal defendido por la FAU, se comprendían por tratarse de una revolución condicionada. Constituía, a pesar de sus limitaciones, una apertura de una vía latinoamericana hacia el socialismo y la libertad. 21

El segundo momento fue el que mostró con toda crudeza las profundas diferencias en el seno de la Federación en torno al tema. Se trató de la polémica periodística mantenida en noviembre de 1961 en Lucha Libertaria entre José Jorge Martínez y Luce Fabbri.22

la liberación de los pueblos cubanos, paraguayo, dominicano, contra todas las dictaduras, siguiendo la línea de condena que expresara la I Conferencia Anarquista Americana de 1957 (Fernández, 2000, p. 85).

20 Lucha Libertaria, enero-febrero 1959, n 189: "Cuba... una esperanza". Estas palabras son representación tanto del apoyo inexorable al proceso revolucionario, como del impacto que éste tuvo en la FAU en sus inicios.

21 Lucha Libertaria, octubre 1960, n² 199: "Por qué apoyamos y de qué defendemos a la Revolución Cubana".

22 Martínez era secretario de FAU en esos momentos y representaba, a decir de Juan Carlos Mechoso (entrevista con el autor, Montevideo, 9/12/2000), la corriente ma- 
A través de ella se supo que las diversas concepciones del anarquismo y su práctica en el seno de FAU arrancaban del debate sobre la Ley Orgánica de la Universidad en 1958. El que se manifestasen ahora parecía casi inevitable: el proceso cubano estaba demasiado lejos de las concepciones tradicionales del anarquismo, y su apoyo no podía darse sin una cierta transformación o renovación de aquellas. Algo a lo que no todo el mundo en FAU estaba dispuesto. ${ }^{23}$ En este debate se enfrentaron dos concepciones teóricas irreconciliables: por una parte, la que denominamos anarquista tradicional, defendida por Fabbri, que planteaba por encima de cualquier otro debate la lucha por la libertad y el anti estatismo, que era contraria al partido único y a toda represión (contrarrevolucionaria y no justificable bajo ningún argumento), y que denunciaba la evolución del castrismo hacia el capitalismo de Estado y el totalitarismo, al igual que había sucedido en Rusia. Por otra parte, la de Nueva Izquierda en la que se enmarcaría el anarquismo de la FAU desde 1964, y que tenía por principales rasgos tercerismo, tercermundismo, antiimperialismo, y latinoamericanismo, así como la defensa de cualquier lucha revolucionaria dado que se entendía que la contradicción fundamental era la que tenía lugar entre imperialismo y liberación, por encima de los errores particulares. En ese caso, y en ese contexto internacional, se hallaba la Revolución Cubana. Para ella negaba el fatalismo hacia el modelo soviético y reivindicaba las vías propias al socialismo de las revoluciones del momento. ${ }^{24}$

El debate en el que se enmarcan ambas posturas era ya viejo en la izquierda, una de las diferencias fundamentales entre anarquismo y marxismo en torno a la revolución, los fines y los medios. Arblaster (1974), al exponer el carácter de la Nueva Izquierda, indica cómo esa polémica era central también en los años sesenta en Europa. Se enfrentaba la concepción libertaria, crítica con el partido revolucionario (vanguardia de las masas) y con las revoluciones desde arriba, a la expuesta por Lenin en ¿Qué Hacer?, don-

yoritaria de la Federación. Fabbri, hija del teórico anarquista italiano Luigi Fabbri, representaba la oposición en el tema. Fue una de las principales referencias teóricas del anarquismo uruguayo, con peso especial en ciertos círculos universitarios.

Ruben Prieto, antiguo militante de Bellas Artes y fundador de la Agrupación Sur y de la FAU, confirma que, una vez pasada la euforia por el triunfo castrista, un análisis más detallado del proceso empezó a mostrar las diferencias internas, ya antes existentes, pero no tan enfrentadas. Desde 1959 ese debate se fue consolidado, y la disensión aumentaba a medida que la Revolución iba definiéndose en un sentido determinado (entrevista con el autor, Montevideo, 21/4/2002).

24 Lucha Libertaria, noviembre 1961, $\mathrm{n}^{2}$ 205: "Polémica en Lucha Libertaria: liberación nacional, el totalitarismo, la revolución en los países desarrollados, Cuba...". 
de defendía la concienciación de los trabajadores desde afuera, por ese partido de vanguardia. Quizá sería excesivo decir que esas dos tendencias fueron las que se enfrentaron en la polémica entre Martínez y Fabbri. Pero en el argumento de la segunda sí que en cierto modo encontramos esa postura. La intelectual uruguaya intuía el fondo ideológico latente de su contraparte al tacharla de influenciada por el marxismo, pues hacia éste evolucionaría más adelante la FAU, de modo que hacia 1972 defendía la importancia del partido revolucionario y de la ideología como respaldo a la acción revolucionaria.

El tercer y definitivo momento del debate en la FAU llegó en mayo de 1962 con una última resolución. 25 Ésta era muestra de la tendencia mayoritaria en la Federación - o al menos la que controlaba sus resortes -, y llegaba para consolidar la tendencia anterior tras los cambios sufridos por la Revolución Cubana (declaración marxista-leninista), retomando los argumentos ya vistos sobre los condicionantes. A través de esta resolución, la dirección de FAU hacía también una exposición clara de sus principios ideológicos: adhesión al principio de autodeterminación de los pueblos frente a cualquier potencia (clave en la lucha por la liberación de pequeños países y de las zonas subdesarrolladas); ratificación de antiimperialismo y tercera posición; postura contraria a la aparición de nuevas oligarquías tras la liquidación de las anteriores y por el crecimiento constante de la autogestión popular (sólo así tienen sentido antiimperialismo y autodeterminación); negación de la identificación del socialismo con el marxismo-leninismo; y valoración de la importancia de la solidaridad de los pueblos (sobre todo subdesarrollados o dependientes) con cualquiera que inicie su lucha liberadora para evitar giros como al que se vio forzada Cuba.

\section{Bases de una nueva concepción revolucionaria}

Con la Revolución Cubana el tema de la revolución y la posibilidad de su realización práctica en el Uruguay pasó también al primer plano del debate libertario. Desde 1959 no sólo se discutía en torno al apoyo a Cuba, también se trasladaba esa experiencia al país y se planteaba su carácter, formas y vías. Nacía y se desarrollaba por tanto una nueva concepción de la revolución que si bien

25 Lucha Libertaria, mayo 1962, $\mathrm{n}^{2}$ 206: "Pleno FAU adoptó importantes acuerdos. Al replantearse $R$. Cubana". 
tenía influencias de etapas anteriores, estaría fundamentalmente mediatizada por el proceso cubano, suponiendo la inserción de un sector del anarquismo uruguayo en la nueva izquierda revolucionaria que se desarrollaba a nivel continental.26 Hacia 1962 las nuevas ideas fueron expuestas en Lucha Libertaria. En ellas encontramos las bases del posterior desarrollo ideológico de FAU y de su concepción revolucionaria:27

a ubicación de la lucha nacional en el contexto latinoamericano y del Tercer Mundo subdesarrollado;

- defensa de la apertura del anarquismo al estudio de otros aportes y experiencias revolucionarias, buscando siempre la originalidad y la vía propia, adaptada a la realidad nacional, no copiando modelos foráneos; 28

- crítica a la izquierda partidaria, sobre todo al PCU, por su apuesta electoral, la no promoción de la experiencia cubana en el Uruguay a través del Comité Coordinador Nacional de Apoyo a la Revolución Cubana, o la espera de la maduración de la situación revolucionaria sin hacer nada para ello;

- negación de la posibilidad de una etapa revolucionaria burguesa en los países subdesarrollados, tal y como mostraba claramente Cuba y como también había argumentado F. Fanon (1987), cita recurrente en aquellos años;

defensa y fomento de las organizaciones populares y de las estructuras de base, por cuanto las masas son las únicas protagonistas de las revoluciones nacionales (G. Gatti) y porque así se crean las condiciones y se incorpora la revolución al abecedario político de los uruguayos;

26 Esta concepción no era unánime en la FAU. Se trataba de aquella que entendemos mayoritaria - por cuanto era la de la dirección y ésta era elegida democráticamente - y que tras la ruptura tuvo continuidad en el grupo continuador de la FAU. Al respecto, y según Ruben Prieto, en los Plenarios esa postura no era mayoría, pero por la dinámica interna conseguían la representación y el control del Comité Federal (entrevista con el autor).

27 Lucha Libertaria, n"206, mayo 1962: "Continuidad histórica de una orientación revolucionaria", J. C. Mechoso; "Trascendencia y superficialidad del año político 1962", J. J. Martínez; "La Revolución y el burocratismo", G. Gatti; n" 207, nov. 1962: "Socialismo - etapas fatales - burguesía nacional", J. C. Mechoso.

28 Esta idea nació entre 1962 y 1963 y se consolidó como proyecto interno en 1967, con las primeras tareas para avanzar en lo que se denominó la Sintesis. Comenzaron las lecturas de autores varios como Mills, Poutlanzas o Luxemburg, así como una revisión de las fuentes propias (Mechoso, 2000, p. 87-88). Resultado de este trabajo sería por ejemplo el documento COPEY, definidor de su estrategia revolucionaria en 1972 (Archivo FAU). 
apuesta por la unidad de las fuerzas de izquierda en todos los ámbitos, y especialmente por el nucleamiento de la izquierda revolucionaria sobre bases comunes de interpretación, sensibilidad y conciencia comprometida;

- búsqueda de una base teórica e ideológica propia para el proceso revolucionario, que no sea traslado ni imposición foránea, y permita dar continuidad a la revolución, más allá de la espontaneidad de su estallido.

Influencia de la Revolución Cubana sería también la definición, en 1962, de las clases protagonistas de la revolución: campesinos, obreros, clases medias, intelectuales y estudiantes, frente a la burguesía nacional y el imperialismo, en un desarrollo de la idea que se impone desde 1959 de contradicción fundamental entre imperialismo y liberación.

\section{La ruptura}

La escisión que sufrió la FAU a principios de 1964 no estuvo relacionada únicamente con las diferentes posturas que se dieron en torno a la Revolución Cubana. Realmente, eso fue sólo una - si bien fundamental - de las tres cuestiones que enfrentaban las dos grandes y opuestas tendencias en el seno de la Federación. Los otros dos problemas eran la prioridad que la organización estaba dando al trabajo en el movimiento obrero con la integración de militantes en los organismos de los trabajadores, y la necesidad que planteaban - los mismos que defendían Cuba y la línea sindical - de comenzar un trabajo de organización que preparase a FAU para los probables tiempos difíciles que vendrían; esto es, iniciar la preparación para el trabajo clandestino. Todo ello se unía además a las distintas concepciones sobre la forma de organizar y estructurar internamente la Federación y sus órganos de decisión, así como sobre el apoyo a los movimientos armados del continente.

La tendencia que podríamos llamar mayoritaria y que desde 1964 mantendría el control de la Federación, estaba encabezada por unos pocos militantes fundadores que desde entonces y por toda la década siguiente hasta el golpe militar serían sus dirigentes: Gerardo y Mauricio Gatti, León Duarte, Roberto Franano o Juan Carlos Mechoso. Algunos eran además militantes sindicales de primer orden y con fuerte peso en la dirección de sus gremios, caso de G. Gatti en el sindicato de Gráficos o L. Duarte en el de FUNSA. Por la otra parte, la figura más destacada - si bien por su prestigio, y no por encabezar orgánicamente el enfrentamiento - 
era la intelectual y profesora de Humanidades Luce Fabbri. Junto a ella se alineaba la Agrupación Anarquista de la Facultad de Bellas Artes, la de Medicina, la Agrupación Sur y la de la Unión (que sí capitalizaba Fabbri).

Las diferencias en torno al apoyo crítico a la Revolución Cubana ya las veíamos en la polémica Martínez versus Fabbri, representativos ambos de las respectivas tendencias. Los otros aspectos están todos estrechamente relacionados, como no podía ser de otra forma al responder en conjunto a distintas formas de entender el anarquismo. Por una parte, y según el testimonio de Ruben Prieto, los grupos que a partir de 1964 no continuaron en FAU abogaban por una organización asamblearia y participativa, que basase su actuación en los plenarios de militantes. Esta postura la habían defendido desde la fundación de la Federación y ya hemos visto que había sido discutida en ocasiones. Desde la otra parte, y según Juan Carlos Mechoso, se entendía que ese hiperfederalismo como lo denominaban -, no era funcional. Para que así ocurriese, deberían existir órganos ejecutivos para el trabajo cotidiano, lo que significaba optar por plenarios deliberativos y que el control de la organización entre congresos recayese en manos de un Consejo Federal. El papel de éste, sus atributos, el mayor o menor centralismo, eran por tanto el eje de esa polémica, que respondía a dos concepciones organizativas muy distintas. Ambas concebían dos tipos de trabajo de masas diferentes. Los representantes de la línea centralizadora eran los grupos con más fuerza en el medio sindical, en donde consideraban que había un día a día que necesitaba de decisiones rápidas que resolvieran los problemas. Los defensores de la línea asamblearia eran aquellos procedentes de medios barriales o estudiantiles, y según Ruben Prieto, ponían el acento en el cambio cultural. 29

Otro punto de fricción lo representaba la evolución de ambos sectores respecto a la violencia y a la necesidad de una organización revolucionaria en el Uruguay. El grupo centralizador abogaba por la preparación organizativa para una radicalización de las luchas y un

29 Ruben Prieto, entrevista con el autor. Según declara, en ocasiones el otro sector era tachado de leninista por su postura frente a la cuestión organizativa, lo que da el tono de la polémica. Por su parte, J. C. Mechoso hoy día se refiere así a la concepción asambleista: "Bellas Artes no tiene urgencias, como nosotros grupo obrero. Ellos tienen su ritmo, hacen su propio proyecto, y lo quieren proyectar a la sociedad. Son cosas a veces muy bonitas, campañas de sensibilización, pero que no hacen a la angustia que está viviendo la gente en un barrio, y los problemas prioritarios que tiene la gente. [A nosotros] lo que nos interesa es ver la apertura de la fuente de trabajo (...) para nosotros las prioridades son otras" (entrevista con el autor, 9/12/2000). 
enfrentamiento con los medios represivos, pues preveían que hacia allí caminaba el país dada la continua agudización de la crisis económica. Esa preparación significaba la creación de estructuras organizativas adecuadas para el trabajo clandestino si fuese preciso; o para el accionar armado, planteamiento que chocaba radicalmente con las ideas anti violencia que representaba el otro sector. ${ }^{30}$

Desde la dirección de FAU un grupo reducido de militantes comenzaron a llevar a la práctica acciones armadas, momentos antes de que se produjese la escisión: en las navidades de 1963 realizaron la primera, los Comandos del hambre, en colaboración con otros grupos de izquierda revolucionaria. ${ }^{31}$ Esta relación, lógica en la línea de quienes mantenían la dirección de FAU - y opuesta a las concepciones de la otra tendencia - había comenzado a gestarse a fines de 1962 cuando algunos grupúsculos radicales se escindían de los partidos de izquierda a los que pertenecían, iniciando un proceso de coordinación y colaboración que con el tiempo daría lugar a la consolidación de las diferentes tendencias existentes en la izquierda revolucionaria en la segunda mitad de la década.

El definitivo proceso de escisión en el seno de la FAU comenzó a fines de 1963, prolongándose las disputas en torno a la disolución o no de la Federación por unos cinco meses. ${ }^{32}$ A partir de abril de 1964 el sector que defendía la opción que hemos definido como centralizadora, se quedó con el nombre de una Federación que para sus oponentes había dejado de existir. Estos crearían en diciembre de ese año la Alianza Libertadora del Uruguay (ALU), ${ }^{33}$ formada, entre otras, por las agrupaciones de Bellas Artes, Medicina y Sur, como intento de organizar a esa tendencia del anarquismo uruguayo. Tuvo una efímera vida, sin repercusiones destacables en la evolución política uruguaya de los siguientes meses. A mediados de 1965 probablemente ya no existía, pues en agosto hay constancia de que muchos de sus fundadores, se habían integrado a otro proyecto más amplio, junto con un grupo de cristianos de izquierda, denominado Centro de Acción Popular (CAP). Como tal editaron una revista, Tarea,

30 Lucha Libertaria, diciembre 1959, nº 188: "Elementos para una ubicación del anarquismo", Luce Fabbri.

31 Se trataba de asaltos a camiones de reparto de supermercados que luego eran distribuidos en barrios pobres de las afueras de Montevideo. Fueron habituales desde esa fecha, y más adelante proporcionarían amplias simpatías en estos sectores al MLNTupamaros.

32 Época, 2/3/64, $\mathrm{n}^{\circ}$ 611: "Resoluciones del Plenario Anarquista del 22 de febrero de 1964". Marcha, 30/4/65 "¿Por qué no callas?”; Lucha Libertaria, abril 1965, $\mathrm{n}^{2} 208$ : "Nuestro Congreso".

33 Marcha, 18/12/64: "Alianza Libertadora del Uruguay". Según Prieto (entrevista con el autor), ALU nació con intención de juntar a los agraviados, pero por todo lo ocurrido ya lo hizo con ánimo de derrotados. 
de la que salieron cuatro números en de 1965. En los artículos de esta revista se aprecia claramente el carácter antiautoritario, opuesto a la violencia, defensor de un socialismo humanista, comunitarista y fuertemente crítico el marxismo-leninismo y con lo que denominaban socialismo autoritario. Algunos miembros del grupo escindido de la FAU y luego participante en ALU y el CAP, desde hacía años también eran partícipes de una significativa experiencia comunitaria: la Comunidad el Sur, que aún existe en la actualidad y a la que siguen perteneciendo algunos de los protagonistas de aquel período. 34

\section{Hacia la acción revolucionaria: FAU entre 1964 y 1967}

Desde que se produjo la escisión a principios de 1964, y hasta su ilegalización a fines de 1967, la evolución de FAU significó la consolidación de las tendencias que se apreciaban desde 1962, y que en buena medida habían sido las causas de sus conflictos internos. La desaparición de la oposición interna dejó las manos libres al grupo que durante estos años controló la Federación para profundizar en una línea ideológica y de trabajo muy definida. ${ }^{35}$ Esas tendencias que ya se manifestaban desde 1962 y que ahora se consolidan, pueden resumirse en los siguientes puntos:

- el apoyo a toda iniciativa de acción directa de contenido revolucionario, especialmente las movilizaciones de los trabajadores cañeros del norte del país iniciadas en 1962;

- la existencia de un Comité Federal que llevaba el peso ejecutivo;

- cambios en algunos aspectos del trabajo orgánico, representados sobre todo en el abandono de la publicación propia, Lucha Libertaria, y por una fuerte militancia en el diario Época desde su nacimiento en 1962;

- $\quad y$, especialmente, el inicio de la coordinación y trabajo clandestino desde fines de 1962, con otros grupos de tendencia revolucionaria con los que tenía además estrecha relación en Época.

34 Sobre la Comunidad del Sur, consúltese Prieto (1986, p. 91-98). Los números de Tarea citados han sido consultados por gentileza de Ruben Prieto.

35 Así lo señala también Mechoso (2000, p. 35-38): tras la división pudieron trabajar en profundidad sus prioridades socio-políticas, adquirieron mayor coherencia en su estrategia, y centraron su militancia, sobre todo, en el medio obrero. En 1965 un Congreso Extraordinario institucionalizó esta orientación ideológica y política con reformas en la Carta Orgánica, la Declaración Política y la aprobación de un Programa de Acción para los siguientes años. 
Todos estos aspectos están íntimamente relacionados. La clave es la línea de acción revolucionaria que establece FAU de forma consecuente con las ideas de su dirección acerca del apoyo a la Revolución Cubana y a los movimientos revolucionarios del continente. En los comités de apoyo a Cuba que se habían creado desde 1959, y que tuvieron su etapa más destacada entre 1961 y 1962, ya propugnaba el aprendizaje de la experiencia cubana y el impulso revolucionario en el país como la mejor forma de ayuda a la consolidación del proceso en la isla, en una visión libertaria de la idea presente en esos años en toda la izquierda revolucionaria y que Guevara había sintetizado en la conocida frase de Crear uno, dos, tres... muchos Vietnam en América Latina. Esa línea revolucionaria y de acción suponía en la práctica la relación con otros grupos de tendencia similar con los que empezaba a compartir espacios comunes, el apoyo a todas las luchas, movilizaciones populares y formas de acción directa que existiesen en el momentos, o el inicio de formas de organización que permitiesen el trabajo clandestino si llegase el caso.

Las relaciones con los otros grupos de tendencia revolucionaria se canalizaron a través de lo que se conoció como el Coordinador de los grupos. Allí se encontraban con militantes socialistas, pro castristras, pro chinos, independientes, ex comunistas, y todos aquellos que en desde principios de la década, y por influencia sobre todo de la Revolución Cubana, comenzaban a buscar otras salidas a la crisis del país y el camino hacia transformaciones revolucionarias (Rey Tristán, 2003). La FAU participó en esta instancia de relación, debate e intercambio prácticamente desde sus inicios, en 1963. Lo hizo a través de un reducido grupo de militantes que en esos momentos tenía también una fuerte presencia en su dirección, y que representaban a aquella tendencia que a partir de 1964 se quedó con su control: Mauricio y Gerardo Gatti, Juan Carlos Mechoso y, en ocasiones, de León Duarte. ${ }^{36}$

La idea que en esos meses se impuso en este sector de la FAU quedaba patente en las declaraciones realizadas en septiembre de 1963 tras la acción policial contra los protagonistas del primer robo de armas con fines políticos que se producía en el país en estos años: el asalto al Club de Tiro Suizo, realizado por otros miembros del Coordinador que más adelante serían el núcleo básico del MLNTupamaros. En ellas expresaban su solidaridad con los que entendían luchan por la verdadera transformación revolucionaria de la sociedad, y cargaban las tintas contra la policía, los políticos, las clases privilegiadas y la prensa. Hacían una obvia lectura política, con un discurso que al tiempo que criticaba duramente a estos colectivos citados,

36 Juan Carlos Mechoso, entrevista con el autor, 9/11/1999. 
defendía indirectamente la legitimidad de la acción de armarse como respuesta. ${ }^{37}$

La FAU participó en el Coordinador hasta que en 1965 las tensiones internas y las diferentes concepciones sobre las vías revolucionarias entre los grupos que lo conformaban provocaron su definitiva disolución. Estuvieron presentes, según Juan Carlos Mechoso, en algunas de las acciones conjuntas de los grupos en estos meses, caso de los citados Comandos del Hambre a fines de 1963, o el robo de la Armería El Cazador en 1964. Pero no compartían el foquismo de los que luego formarían el MLN-Tupamaros, ni las concepciones pro chinas del MIR. En 1964, rechazaron las propuestas de Raúl Sendic de formación de un polo revolucionario, una nueva organización que aglutinase a todas las tendencias revolucionarias de los grupos de izquierda existentes en el momento, puesto que ellos no eran una tendencia en un grupo, sino una organización que como tal tenía esa orientación. ${ }^{38}$ Además, diferían de forma significativa en la estrategia a seguir por ese polo revolucionario. Cuando en 1965 , tras una grave crisis del Coordinador, se dieron los pasos definitivos para la creación de una organización revolucionaria, el MLN-Tupamaros, la FAU decidió no participar por divergencias tácticas y teóricas.

Además del Coordinador, hubo dos espacios comunes para la izquierda revolucionaria muy significativos en los que la FAU también participó y a las que ya hemos hecho referencia: el diario Época y las movilizaciones cañeras. Colaboraron con la organización de estas últimas desde el Coordinador, y participaron incluso acompañándolas. Para la FAU, la lucha de los trabajadores cañeros era reflejo de las posturas respecto a la acción directa en la izquierda del momento. Si bien en sus inicios había suscitado apoyos diversos por su impacto, ya en 1965 aquellos se veían mediatizados por los enfoques políticos y revolucionarios de las distintas fuerzas de izquierda. Consideraban que había servido para definir actitudes. Para saber quienes están comprometidos en esta acción revolucionaria que se procesa y quienes duermen en propósitos y declaraciones que en nada afectan al régimen y sus sostenedores. Además, defendía su contenido revolucionario por lo que suponía de ataque directo al régimen capitalista, implícito en el reclamo de poner en manos de los trabajadores el medio de producción fundamental de nuestro país, así como por el ejemplo que proporcionaba. ${ }^{39}$ En 1965, como motivo de una marcha por la expropiación de

37 Marcha, 29/9/63: "Ante la infamia"; y Época, 15/9/63, n² 451: "El país cruje". Ni FAU ni ninguno de sus representantes en el Coordinador, participaron.

38 Juan Carlos Mechoso, entrevista con el autor, 9/11/1999.

39 Lucha Libertaria, abril 1965, n" 208: "Marcha por la Tierra. Una lucha que define", E. Lemos. 
la tierra, firmaron un manifiesto conjunto sobre ella con el FAR y el PSU. Este hecho reflejaba la línea de trabajo que se imponía en esos momentos en la FAU: colaboración con otros grupos revolucionarios (excluidos los que defendían el electoralismo y el parlamentarismo como vía para la transformación de la sociedad) y rechazo al sectarismo.40

La publicación del diario Época tuvo una segunda etapa, que si bien fue muy breve (5 días en diciembre de 1967), fue clave en la evolución de la izquierda revolucionaria en su momento. En el primero de ellos (día 7), había aparecido en sus páginas lo que en su momento se denominó el Acuerdo de Época, declaración que recogía los postulados de la Organización Latinoamericana de Solidaridad41 y defendía la acción revolucionaria en el Uruguay. Esta declaración fue el motivo de que el día 12 de diciembre fuese clausurado el diario, y con él ilegalizadas todas las fuerzas políticas firmantes, entre ellas la FAU. Esto supuso el fin anticipado de la coordinación y del intento de creación de algún tipo de polo revolucionario en el país, que se había gestado en los cinco años anteriores, y que había tenido su impulso definitivo tras el intenso debate generado por la Conferencia de la OLAS.

La ilegalización fue punto de inflexión. Desde entonces, la FAU profundizaría en la línea de organización clandestina y acción revolucionaria, con una estructura cada vez más centralizada, a la que su sector dominante apuntaba desde 1962, si bien las líneas básicas de trabajo tuvieron sus inicios entre 1964 y 1967: en la actividad sindical, la coordinación con otros grupos de orientación combativa en la Tendencia, nacida a fines de 1966, y que si bien representaba la minoría en la CNT, era la que dominaba la movilización social del momento; en ella se desarrollaría la más fuerte organización de masas del anarquismo en el período: la Resistencia Obrera Estudiantil, caracterizada por su línea combativa y de acción en las luchas de los trabajadores y estudiantes. Y en la actividad clandestina

40 Lucha Libertaria, abril 1965, n² 208, p. 4, "Acción conjunta de los grupos revolucionarios". Estos argumentos parecen habituales en la nueva izquierda de la época. Arblaster (1974, p. 21) lo refleja también en el caso de un delegado británico en una conferencia internacional de anarquistas en esos años.

41 OLAS, celebrada en agosto de ese año en La Habana, y que había pretendido ser algo así como una internacional revolucionaria dirigida por Cuba. Sus conclusiones defendían la lucha revolucionaria en el continente bajo el modelo cubano teorizado por el Che y Debray (OLAS, 1967). La participación en la OLAS se había hecho a través de comités nacionales y el uruguayo, capitalizado por el PCU, no había dado entrada al resto de fuerzas políticas (a excepción del PSU), que defendían posturas más radicales o revolucionarias, precisamente aquellas que finalmente fueron mayoría en la conferencia. El debate generado por constitución del Comité Nacional mostró claramente la división en la izquierda uruguaya entre PCU y el resto de los grupos. 
revolucionaria, el desarrollo de estructuras para tal efecto, como la Organización Popular Revolucionaria - 33 Orientales, que compartió protagonismo con el MLN-Tupamaros, aunque a menor escala, en la lucha revolucionaria en el Uruguay entre 1969 y 1972. Ambas organizaciones, coordinadas por un centro político director (la ilegalizada dirección de FAU) y con la insurrección como método revolucionario (formulada en su versión definitiva en el documento COPEY en 1972), fueron los elementos claves de la nueva concepción revolucionaria de este sector del anarquismo uruguayo desde 1968.

\section{Referencias bibliográficas}

ARBLASTER, Anthony. El anarquismo y la Nueva Izquierda. Madrid: Zero, 1974.

CORES, Hugo. La Lucha de los Gremios Solidarios (1947-1952). Montevideo: Compañero-Banda Oriental, 1989.

FANON, Frantz. Los condenados de la Tierra. México: FCE, 1987.

FERNÁNDEZ, Frank. El Anarquismo en Cuba. Madrid: Fundación Anselmo Lorenzo, 2000.

MECHOSO, Juan Carlos: Acción directa anarquista. Una historia de FAU. Montevideo: Recortes, 2002.

OLAS. Primera Conferencia de la Organización Latinoamericana de Solidaridad. La Habana: 1967.

PRIETO, Rubén Gerardo. Por la tierra y por libertad. Trabajadores rurales y proceso revolucionario. UTAA y el MNL-T (Movimiento Nacional de Lucha por la Tierra). Montevideo: Nordam, 1986.

REY TRISTÁN, Eduardo. Identidad revolucionaria y cultura política en los sesenta: Cuba y la izquierda radical uruguaya. In: BALBOA, Xesús y PERNAS OROZA, Herminia: Entre nós: estudios de arte, xeografía e historia en homenaxe ó profesor Xosé Manuel Pose Antelo. Santiago de Compostela: Universidad de Santiago, 2001, p. 507-537.

REY TRISTÁN, Eduardo. La influencia de la Revolución Cubana en la izquierda uruguaya: el Movimiento de Solidaridad con Cuba (1959-1965). In: CAMPOS ÁLVAREZ, José Ramón y REY TRISTÁN, Eduardo: Actas del III Congreso Internacional de Historiadores Latinoamericanistas (ADHILAC) (2001). Santiago de Compostela: 2002.

REY TRISTÁN, Eduardo. Propuestas revolucionarias en la izquierda uruguaya de los años 60. Revista de Historia de América, México: Instituto Panamericano de Geografía e Historia, vol. 132, 2003 (en prensa).

SOLARI, Aldo. El tercerismo en Uruguay. In: REAL DE AZÚA, Carlos: Tercera posición, Nacionalismo Revolucionario y Tercer Mundo. Una teoría de sus supuestos. Montevideo: Cámara de Representantes República Oriental del Uruguay, 1990, t. 3. 